\title{
Infectious keratitis after corneal crosslinking for keratoconus caused by levofloxacin- resistant microorganisms
}

\author{
Naoko Kato ${ }^{1,2 *}$, Takeshi Ide ${ }^{3}$, Hidenaga Kobashi ${ }^{2}$ and Ikuko Toda ${ }^{1}$
}

\begin{abstract}
Introduction: We present seven cases of infectious keratitis after corneal crosslinking (CXL) to attenuate keratoconus progression.

Methods: Of 524 consecutive patients who underwent CXL, 7 cases (4 males and 3 females; $21.5 \pm 7.1$ years) developed postoperative infectious keratitis were retrospectively reviewed. CXL was performed using the Dresden protocol or an accelerated protocol involving epithelial removal.

Results: All cases appeared normal on the day after surgery, but subsequently developed eye pain, blurred vision, corneal infiltration, inflammation of the anterior chamber, and ciliary injection on day 2 or 3 . Methicillin-resistant Staphylococcus aureus was cultured from two eyes, methicillin-sensitive Staphylococcus aureus from two eyes, and Streptococcus pneumoniae from one eye. All detected bacteria were resistant to levofloxacin (LVFX). Five of the seven cases, especially four of the five severe cases with hypopyon, had a history of atopic dermatitis. All cases were observed after 2015.

Conclusions: Infectious keratitis after CXL caused by microbes resistant to LVFX is increasing. In addition to careful postoperative observation of the cornea, preoperative evaluation of bacteria within the conjunctival sac evident on nasal swab cultures may be useful to identify potentially problematic microbes and inform the selection of appropriate antibiotics.
\end{abstract}

Keywords: Infectious keratitis, Corneal crosslinking, Levofloxacin-resistant, Methicillin- resistant Staphylococcus aureus, Methicillin-sensitive Staphylococcus aureus

\section{Introduction}

Corneal crosslinking (CXL) attenuates keratoconus progression, as first reported by Wollensak et al. in 2003 [1]. Progression was halted in $90-95 \%$ of cases in clinical trials [2-5]. However, several rare complications have been described, including delayed epithelial healing $[6,7]$, stromal melting $[7,8]$, sterile infiltration [8-10],

\footnotetext{
* Correspondence: naokato@bc.iij4u.or.jp

'Minamiaoyama Eye Clinic, Kitaaoyama 3-3-11, Minato-ku, 107-0061 Tokyo, Japan

${ }^{2}$ Department of Ophthalmology, School of Medicine, Keio University, Tokyo, Japan

Full list of author information is available at the end of the article
}

early infectious keratitis [11-21], stromal hazing and demarcation after several weeks [9], deep stromal scarring [22], failure [9], and progressive flattening [23, 24]. Infectious keratitis is the most concerning complication; scarring and irregular astigmatism may develop even after infection control, thus impairing the vision of young patients. We first used CXL to treat keratoconus 13 years ago, and encountered no case of infectious keratitis up to 2015. Sporadic cases were noted from 2016 onward (Table 1); these cases are summarized in this paper, including the possible causes and preventative measures and treatments that we employ. 
Table 1 Demographic of cases with infectious keratitis after CXL at Minamiaoyama Eye Clinic

\begin{tabular}{lccc}
\hline & Number of cases with infection & Number of CXL & Frequency (\%) \\
\hline 2007 & 0 & 3 & 2 \\
2008 & 0 & 10 & 0.0 \\
2009 & 0 & 12 & 0.0 \\
2010 & 0 & 8 & 0.0 \\
2011 & 0 & 5 & 0.0 \\
2012 & 0 & 4 & 0.0 \\
2013 & 0 & 45 & 0.0 \\
2014 & 0 & 52 & 0.0 \\
2015 & 0 & 5 & 0.0 \\
2016 & 2 & 46 & 4.4 \\
2017 & 0 & 60 & 0 \\
2018 & 1 & 92 & 1.1 \\
2019 & 3 & 134 & 2.2 \\
2020 & 1 & 51 & 2.0 \\
Total & 7 & 524 & 1.3 \\
\hline
\end{tabular}

\section{Patients}

From February 2007 to May 2020, 524 consecutively enrolled eyes of keratoconus patients, exhibiting pellucid marginal degeneration or keratectasia after laser in-situ keratomileusis, underwent CXL with epithelial debridement under topical anesthesia with application of oxybuprocaine hydrochloride $(0.4 \% \mathrm{w} / \mathrm{v})$ eyedrops before each procedure. After the eye lid skin was delicately rubbed 2 times using a sterilized cotton swab soaked in the $10 \%$ povidone-iodine solution, a lid speculum was inserted. The eye surface was rinsed with $20 \mathrm{ml}$ of $5 \mathrm{ppm}$ ozone water, followed by removal of the central corneal epithelium (diameter $=7.0-8.0 \mathrm{~mm}$ ) using a blunt spatula or an excimer laser. Then, $0.1 \%(\mathrm{w} / \mathrm{v})$ isotonic riboflavin in dextran $20 \%(\mathrm{w} / \mathrm{v})$ solution was instilled every $2 \mathrm{~min}$ for $20 \mathrm{~min}$. After confirming stromal riboflavin saturation via slit-lamp examination, the thinnest part of the corneal stroma was measured using an AL-3000 pachymeter (Tomey, Aichi, Japan). If the stromal thickness was $<400 \mu \mathrm{m}, 0.1 \%(\mathrm{w} / \mathrm{v})$ hypotonic riboflavin or distilled water was instilled until the minimal thickness reached $400 \mu \mathrm{m}$. UV-A radiation was then delivered at $3.0 \mathrm{~mW} / \mathrm{cm}^{2}$ for $30 \mathrm{~min}$ (KERA-X; Peschke, Huenenberg, Switzerland) or $18.0 \mathrm{~mW} / \mathrm{cm}^{2}$ for $5 \mathrm{~min}$ (KXL; Avedro, Waltham, MA, USA). At the end of the procedure, a soft bandage contact lens was applied and a drop of levofloxacin (LVFX) instilled. Postoperative medications included LVFX and betamethasone $(0.1 \% \mathrm{w} / \mathrm{v})$ eyedrops four times daily.

The study protocol was approved by the Internal Review Board of Minamiaoyama Eye Clinic. While this study was the retrospective observational study, the written informed consent was waived by the Internal Review
Board of Minamiaoyama Eye Clinic. In all cases, the CXL was performed by experienced ophthalmologists.

The characteristics of the seven patients are summarized in Table 2: bacterial infections were proven or strongly suspected in all patients. Microbiological evaluations were performed for five patients; methicillinresistant Staphylococcus aureus (MRSA) was cultured from two eyes, methicillin-sensitive Staphylococcus aureus from two eyes, and Streptococcus pneumoniae from one eye. All detected bacteria were resistant to LVFX. Four experienced surgeons performed the CXL for the seven cases, and there was no remarkable prevalence among individuals.

Five patients (1, 3, 4, 5 and 7) exhibited severe infectious keratitis with hypopyons. One patient (Case 1) underwent implantation of a pair of Ferrara rings contemporaneously with CXL. All five patients with severe keratitis appeared normal on the day after surgery, but complained of eye pain on day 2 or 3 . All patients exhibited corneal epithelial defects accompanied by infiltration, ciliary injection, and a hypopyon on day 3. The infections were controlled by antibiotics, and the corneas healed but with stromal scarring. In the two patients without hypopyons, two (Cases 2 and 6) complained of pain on day 2 or 3 and were diagnosed with infectious keratitis on day 3 . These two patients recovered quickly after application of topical antibiotics, without stromal scarring.

\section{Discussion}

We encountered 7 cases (among 524 cases; rate of $1.34 \%$ ) of infectious keratitis after CXL to treat keratoconus, all within the past 5 years. MRSA and MRSA 
Table 2 Characteristics of cases with infectious keratitis after corneal crosslinking

\begin{tabular}{|c|c|c|c|c|c|c|c|c|c|c|}
\hline Case & Age & Gender & $A D$ & $\begin{array}{l}\text { Year of } \\
\text { surgery }\end{array}$ & Microbes & $\begin{array}{l}\text { Sensitivity } \\
\text { for } \\
\text { antibiotics }\end{array}$ & Hypopyon & Clinical course & $\begin{array}{l}\text { Antibiotics } \\
\text { used for } \\
\text { treatment }\end{array}$ & Others \\
\hline 1 & 21 & M & + & 2016 & MRSA & $\begin{array}{l}\text { R; LVFX, } \\
\text { CTZ, EM } \\
\text { S; VCM }\end{array}$ & + & $\begin{array}{l}\text { Pain on day } 3 \\
\text { healed with scar, } \\
\text { eventual PKP }\end{array}$ & VCM & $\begin{array}{l}\text { Ferrara ring implantation was } \\
\text { performed simultaneously } \\
\text { with } C X L\end{array}$ \\
\hline 2 & 33 & $\mathrm{~F}$ & - & 2016 & $\begin{array}{l}\text { St } \\
\text { pneumoniae }\end{array}$ & $\begin{array}{l}\text { R; EM } \\
\text { l; LVFX } \\
\text { S; CTZ }\end{array}$ & - & $\begin{array}{l}\text { Pain on day } 2, \\
\text { Diagnosed on day } 3\end{array}$ & $\mathrm{CTZ}$ & \\
\hline 3 & 15 & M & + & 2018 & MSSA & $\begin{array}{l}\text { R; LVFX } \\
\text { S; CTZ }\end{array}$ & + & $\begin{array}{l}\text { Pain on day } 2, \\
\text { Diagnosed on day } 3\end{array}$ & $\mathrm{CTZ}$ & \\
\hline 4 & 20 & M & - & 2019 & Not tested & NA & + & $\begin{array}{l}\text { Pain on day } 2, \\
\text { Diagnosed on day } 3\end{array}$ & TOB, CP, CTZ & \\
\hline 5 & 25 & $\mathrm{~F}$ & + & 2019 & MSSA & $\begin{array}{l}\text { R; LVFX, EM } \\
\mathrm{S} ; \mathrm{CTZ}\end{array}$ & + & $\begin{array}{l}\text { Pain and visual } \\
\text { disturbance on day } \\
2 \\
\text { Corneal perforation } \\
\text { on day } 3\end{array}$ & TOB, CTZ & \\
\hline 6 & 16 & M & + & 2019 & Not tested & NA & - & Diagnosed on day 3 & TOB, CP, CTZ & \\
\hline 7 & 16 & $\mathrm{~F}$ & + & 2020 & MRSA & R; LVFX, CTZ & + & $\begin{array}{l}\text { Pain and diagnosed } \\
\text { on day } 2\end{array}$ & VCM & \\
\hline
\end{tabular}

$A D$ atopic dermatitis; $R$ resistant; $S$ sensitive; $P K P$ penetrating keratoplasty; $L V F X$ levofloxacin; CTZ ceftazidime; $E M$ erythromycin; VCM vancomycin; TOB tobramycin; CXL corneal crosslinking, MRSA methicillin-resistant Staphylococcus aureus; MSSA methicillin-sensitive Staphylococcus aureus; St

pneumoniae Streptococcus pneumoniae

resistant to LVFX were the most frequent causative microbes, followed by $S$. pneumoniae (also resistant to LVFX). The frequency of infectious keratitis after CXL has been reported by several clinicians; the microbes involved were gram-positive bacteria (Staphylococcus epidermidis[21], S. aureus[11-16] and Streptococcus salivarius and/or S. oralis[17, 18]); gram-negative bacteria (Escherichia coli[19] and Pseudomonas aeruginosa[20]), herpes virus[25], and a fungus and Acanthamoeba[26]. Many microbes were resistant to the new quinolone antibiotics, similar to our findings.

As stated above, post-CXL infections were not observed until 2016 in our institute. In the 9 years from 2007 to 2015, we performed CXL on 141 eyes and experienced no case of infection. After the first case in 2016, the incidence increased to 3 of 134 eyes (2.2\%) in 2019 (Table 1).

We used ofloxacin eyedrops until 2000, and later LVFX eyedrops from 2001 still now, as preventative therapies after CXL, PRK, and PTK. The new quinolone antibiotics, such as LVFX, gatifloxacin, and moxifloxacin, have widely been used to prevent infection after various ophthalmological surgeries. The trends in antibiotic resistance among ocular microorganisms have been investigated. Asbell et al. showed that antibiotic resistance was prevalent among staphylococcal isolates, but only a few small changes were observed from 2009 to 2018 in the USA. [27, 28] Deguchi et al. found that the prevalence of MRSA and methicillin-resistant-coagulase-negative staphylococci (MR-CNS) decreased significantly from 2005 to 2014 in Japan, but over $50 \%$ of
Corynebacteriumisolates remained resistant to LVFX[29]. Kamo et al. showed that the prevalence of LVFX-resistant MSSA increased significantly from 2008 to 2018, although the prevalence of MRSA did not increase. MR-CNS was not detected in 2008.[30, 31] Thus, microorganisms resistant to new quinolone antibiotics may have increased in recent years, raising the rate of postoperative infectious keratitis.

A history of atopic dermatitis may increase the risk of post-CXL infection. Skin MRSA levels are elevated in patients with atopic dermatitis[13, 32, 33]. Five of the seven patients $(71 \%)$ in this study had been diagnosed with atopic dermatitis, including four of the five $(80 \%)$ with severe infectious keratitis accompanied by a hypopyon. Patients on long-term steroids or immunosuppressants to treat allergic disorders, such as vernal keratoconjunctivitis, bronchial asthma, and eczema, require special attention in terms of the evaluation of drug-resistant bacteria, especially those with atopic dermatitis. Although there were no healthcare workers among our patients, that group also requires special attention because they frequently come into contact with drug-resistant bacteria[33]..

In this study, all symptoms of infection became apparent on postoperative day 2 to 3; no symptoms were noted on day 1 . Postoperative examinations should be performed on day 2 or 3; if suspicious symptoms are seen, immediate microbiological testing (including for drug sensitivity) is required. We recently began to preoperatively screen for microbes via nasal culture; the conjunctival sac is seldom culture-positive when patients 
do not develop conjunctivitis. Furthermore, we prescribe additional effective antibiotics, such as chloramphenicol, postoperatively, if some bacteria resistant to LVFX and/ or other drugs were detected.

In conclusion, postoperative infectious keratitis after CXL is caused mainly by LVFX-resistant bacteria. As microbial resistance to the new quinolone antibiotics has increased recently, drug-resistant bacteria on the ocular surface, especially in patients with atopic dermatitis, should be screened for in patients undergoing CXL for keratoconus.

\section{Acknowledgements}

The authors wish to acknowledge Daisuke Todokoro, M.D., Ph.D., Department of Ophthalmology, Gunma University Graduate School of Medicine and Junko Kamo, M.D., Ph.D., Department of Ophthalmology, Kofu Kyoritsu Hospital for their valuable discussion and support for conceptualization of the manuscript.

\section{Authors' contributions}

NK analyzed and interpreted the patient data, and drafted the manuscript, TI, HK and IT made contributions to conception and revising critically the manuscript for important intellectual content. All authors read and approved the final manuscript.

\section{Funding}

No funding was obtained for this work.

\section{Availability of data and materials}

All data generated or analyzed during this study are summarized in this published article as Table 2 .

\section{Declarations}

\section{Ethics approval and consent to participate}

This retrospective observational study was approved by the Internal Review Board of Minamiaoyama Eye Clinic, and the study protocol was conducted in accordance with the tenets of the Declaration of Helsinki. While this study was the retrospective observational study, the written informed consent was waived by the Internal Review Board of Minamiaoyama Eye Clinic.

\section{Consent for publication}

Not applicable.

\section{Competing interests}

The authors declare that they have no competing interests.

\section{Author details}

'Minamiaoyama Eye Clinic, Kitaaoyama 3-3-11, Minato-ku, 107-0061 Tokyo, Japan. ${ }^{2}$ Department of Ophthalmology, School of Medicine, Keio University, Tokyo, Japan. ${ }^{3}$ Tokyo Vision Eye Clinic Asagaya, Tokyo, Japan.

Received: 20 February 2021 Accepted: 14 August 2021

Published online: 31 August 2021

\section{References}

1. Wollensak G, Spoerl E, Seiler T. Riboflavin/ultraviolet-a-induced collagen crosslinking for the treatment of keratoconus. Am J Ophthalmol. 2003; 135: 620-627.

2. Raiskup-Wolf F, Hoyer A, Spoerl E, et al. Collagen crosslinking with riboflavin and ultraviolet-A light in keratoconus: long-term results. J Cataract Refract Surg. 2008; 34: 796-801.

3. Wittig-Silva C, Whiting M, Lamoureux E, et al. Randomized controlled trial of corneal collagen cross-linking in progressive keratoconus: preliminary results. J Refract Surg. 2008; 24: S720-725.

4. Hersh PS, Stulting RD, Muller D, et al. United States Crosslinking Study Group. United States Multicenter Clinical Trial of Corneal Collagen
Crosslinking for Keratoconus Treatment. Ophthalmology. 2017; 124: 12591270.

5. Kobashi H, Rong SS. Corneal Collagen Cross-Linking for Keratoconus: Systematic Review. Biomed Res Int. 2017:2017:8145651.

6. Mohamed-Noriega K, Butrón-Valdez K, Vazquez-Galvan J, et al. Corneal melting after collagen cross-linking for keratoconus in a thin cornea of a diabetic patient treated with topical nepafenac: A case report with a literature review. Case Rep Ophthalmol. 2016; 7: 119-124.

7. Seiler TG, Schmidinger G, Fischinger I, et al. Complications of corneal crosslinking. Complications of corneal cross-linking. Ophthalmologe. 2013; 110: 639-644.

8. Sasaki T, Ide T, Toda I, et al. Amniotic Membrane Transplantation as a Treatment for sterile infiltration and corneal melting after corneal crosslinking for keratoconus. Case Rep Ophthalmol. 2018; 9: 185-189.

9. Koller T, Mrochen M, Seiler T. Complication and failure rates after corneal crosslinking. J Cataract Refract Surg 2009; 35: 1358-1362.

10. Mereaux D, Knoeri J, Jouve L, et al. Sterile keratitis following standard corneal collagen crosslinking: A case series and literature review. J Fr Ophtalmol. 2019; 42: 603-611.

11. Shetty R, Kaweri L, Nuijts RM, et al. Profile of microbial keratitis after corneal collagen cross-linking. Biomed Res Int. 2014;2014:340509.

12. Kodavoor SK, Sarwate NJ, Ramamurhy D. Microbial keratitis following accelerated corneal collagen cross-linking. Oman J Ophthalmol. 2015; 8: 111-3.

13. Fasciani R, Agresta A, Caristia A, et al. Methicillin-Resistant Staphylococcus aureus Ocular Infection after Corneal Cross-Linking for Keratoconus: Potential Association with Atopic Dermatitis. Case Rep Ophthalmol Med. 2015;2015:613273

14. Oakey Z, Thai K, Garg S. Bilateral corneal perforation due to MRSA keratitis in a crosslinking patient. GMS Ophthalmol Cases. 2017;7: Doc21.

15. Kodavoor SK, Tiwari NN, Ramamurthy D. Profile of infectious and sterile keratitis after accelerated corneal collagen cross-linking for keratoconus. Oman J Ophthalmol. 2020; 13: 18-23.

16. Schear M, Ragam A, Seedor J, et al. Rapid keratitis and perforation after corneal collagen cross-linking. Am J Ophthalmol Case Rep. 2020; 18: 100658

17. Al-Amry M, Mudhaiyan T, Al-Huthail R, et al. Infectious crystalline keratopathy after corneal cross-linking. Middle East Afr J Ophthalmol. 2017; 24: $100-102$.

18. Zamora KV, Males JJ. Polymicrobial keratitis after a collagen cross-linking procedure with postoperative use of a contact lens: a case report. Cornea. 2009: 28: 474-476.

19. Pollhammer $M$, Cursiefen C. Bacterial keratitis early after corneal crosslinking with riboflavin and ultraviolet-A. J Cataract Refract Surg. 2009: 35: 588-589.

20. Sharma N, Maharana P, Singh G, et al. Pseudomonas keratitis after collagen crosslinking for keratoconus: case report and review of literature. J Cataract Refract Surg. 2010; 36: 517-520.

21. Pérez-Santonja JJ, Artola A, Javaloy J, et al. Microbial keratitis after corneal collagen crosslinking. J Cataract Refract Surg. 2009; 35: 1138-1140.

22. Kato N, Konomi K, Saiki M, et al. Deep stromal opacity after corneal crosslinking. Cornea. 2013; 32: 895-898.

23. Kato N, Negishi K, Sakai C, et al. Five-year Outcomes of Corneal CrossLinking for Keratoconus: Comparison Between Conventional and Accelerated Procedures. Cornea. 2020; 39: e1.

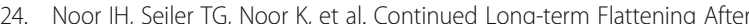
Corneal Cross-linking for Keratoconus. J Refract Surg. 2018; 34: 567-570.

25. Sitaula S, Singh SK, Gurung A. Bilateral viral keratitis following corneal collagen crosslinking for progressive keratoconus. J Ophthalmic Inflamm Infect. 2019; 9: 16

26. Maharana PK, Sahay P, Sujeeth M, et al. Microbial Keratitis After Accelerated Corneal Collagen Cross-Linking in Keratoconus. Cornea. 2018; 37: 162-167.

27. Asbell PA, DeCory HH. Antibiotic resistance among bacterial conjunctival pathogens collected in the Antibiotic Resistance Monitoring in Ocular Microorganisms (ARMOR) surveillance study. PLoS One. 2018; 13: e0205814.

28. Asbell PA, Sanfilippo CM, Sahm DF, et al. Trends in Antibiotic Resistance Among Ocular Microorganisms in the United States From 2009 to 2018 JAMA Ophthalmol. 2020; 138: 1-12.

29. Deguchi H, Kitazawa K, Kayukawa K, et al. The trend of resistance to antibiotics for ocular infection of Staphylococcus aureus, coagulase-negative staphylococci, and Corynebacterium compared with 10-years previous: A retrospective observational study. PLoS One. 2018; 13: e0203705. 
30. Kamo J, Soshiu M, Muramatsu S, et al. Change in conjunctivitis bacteria susceptibilities to antibiotics between 2008 and 2011. J Eye 2014; 31: 10371042.

31. Kamo J, Muramatsu S, Akazawa $\mathrm{H}$, et al. Recommendation of antibiotics for the eyes by age group in 2018 based on microorganism sensitivity. J Eye 2020; 37: 484-489.

32. Fukuda $M$, Ohashi $H$, Matsumoto $C$, et al. Methicillin-resistant Staphylococcus aureus and methicillin-resistant coagulase-negative Staphylococcus ocular surface infection efficacy of chloramphenicol eye drops. Cornea. 2002; 21: 586-89.

33. Kitazawa K, Sotozono C, Sakamoto M, et al. Nasal and conjunctival screening prior to refractive surgery: an observational and cross-sectional study. BMJ Open. 2016; 6: e010733

\section{Publisher's Note}

Springer Nature remains neutral with regard to jurisdictional claims in published maps and institutional affiliations.

Ready to submit your research? Choose BMC and benefit from:

- fast, convenient online submission

- thorough peer review by experienced researchers in your field

- rapid publication on acceptance

- support for research data, including large and complex data types

- gold Open Access which fosters wider collaboration and increased citations

- maximum visibility for your research: over $100 \mathrm{M}$ website views per year

At BMC, research is always in progress.

Learn more biomedcentral.com/submissions 